\title{
Penataan Objek Wisata Sebagai Strategi Komunikasi Dinas Pariwisata Dan Kebudayaan Dalam Kegiatan Visit Batam 2010
}

\author{
Angel Purwanti \\ Dosen Ilmu Komunikasi Universitas Putera Batam \\ angel.purwanti@gmail.com
}

\begin{abstract}
Communication strategy as an activity or communication campagne used to information or persuades to build understanding and forced an idea or cases, product or service that is planned. Batam tourism increasing is by Visit Batam. One strategy would be communicated by the Department of Tourism and Culture Batam namely Arrangement and Infrastructure Improvement. The approach used in structuring and improving the infrastructure and the revitalization of Jodoh and Nongsa structuring, development and upgrading of roads Batam city, and the management and urban utility increasing. This research as a qualitative research with descriptif-case study approaching. Data source used depth interview, observation and documentations.
\end{abstract}

Keyword : Communication Strategy, Case Study, Qualitative Research, descriptive

\begin{abstract}
Abstrak
Strategi komunikasi merupakan kegiatan atau kampanye komunikasi yang sifatnya informasial maupun persuasive untuk membangun pemahaman dan dukungan terhadap suatu ide, gagasan atau kasus, produk maupun jasa yang terencana. Peningkatan Pariwisata Kota Batam dilakukan dengan bentuk kegiatan Visit Batam. Salah satu trategi yang di komunikasikan oleh Dinas Pariwisata dan Kebudayaan Kota Batam yaitu Penataan dan Peningkatan Infrastruktur. Pendekatan yang dilakukan dalam penataan dan peningkatan infrastruktur yaitu revitalisasi dan penataan kawasan Jodoh dan Nongsa, pembangungan dan peningkatan jalan Kota Batam, dan pengelolaan dan pengingkatan utilitas perkotaan. Penelitian ini merupakan penelitian kualitatif dengan pendekatan studi kasus yang bersifat deskriptif. Pengumpulan data dilakukan dengan cara wawancara mendalam, observasi dan dokumentasi.
\end{abstract}

Kata Kunci: Strategi komunikasi, Studi Kasus, Penelitian Kualitatif, Deskriptif 


\section{PENDAHULUAN}

Kota Batam memiliki banyak potensi pariwisata. Potensi pariwisata yang sedang berkembang di Pulau Batam saat ini adalah pariwisata belanja, hal ini banyak ditandai banyaknya pembangunan mallmall di berbagai tempat yang ada di pulau Batam. Batam memiliki beberapa tempat wisata yang dijadikan sebagai wisata religi. Kawasan yang selalu dikunjungi oleh wisatawan mancanegara maupun lokal adalah Vihara Maha Duta Meitreya, yang merupakan salah satu Vihara terbesar di Asia Tenggara. Letaknya yang stategis yang dekat dengan Singapura dan Malaysia, menjadikan Vihara ini ramai dikunjungi oleh ummat Budha baik untuk beribadah maupun melihat keagungan Vihara ini.

Ada juga makam Nong Isa - Nongsa. Nong Isa merupakan salah satu penduduk asli Pulau Batam, di mana berkat hasil kerja keras beliau mampu memajukan daerah Nongsa pada awal berdirinya Batam. Nongsa saat itu dikenal sebagai pelabuhan yang banyak disinggahi pedagang sebelum menuju ke Singapura dan Semenanjung Malaysia.

Kota Batam adalah kota terbesar di provinsi Kepulauan Riau, Indonesia, dengan jumlah penduduk mencapai 1.025.044 jiwa. Metropolitan Batam terdiri dari tiga pulau yaitu Batam, Rempang, dan Galang yang dihubungkan oleh Jembatan Barelang. Batam merupakan salah satu kota dengan pertumbuhan terpesat di Indonesia. Ketika dibangun pada tahun 1970-an awal kota ini hanya dihuni sekitar 6.000 penduduk. Dan dalam tempo 40 tahun penduduk Batam bertumbuh hingga 170 kali lipat.

Kota Batam merupakan sebuah pulau yang terletak sangat strategis di sebelah utara Indonesia dan terletak di jalur pelayaran internasional. Masyarakat Kota Batam merupakan masyarakat heterogen yang terdiri dari beragam suku dan golongan.

Pada tahun 1970-an Batam mulai dikembangkan sebagai basis logistik dan operasional untuk industri minyak dan gas bumi oleh Pertamina. Kemudian berdasarkan Kepres No. 41 tahun 1973, pembangunan Batam dipercayakan kepada lembaga pemerintah yang bernama Otorita Pengembangan Industri Pulau Batam atau sekarang dikenal dengan Badan Pengusahaan Batam (BP Batam). Dalam rangka melaksanakan visi dan misi untuk mengembangkan Batam, maka dibangun berbagai insfrastruktur modern yang berstandar internasional serta berbagai fasilitas lainnya, sehingga diharapkan mampu bersaing dengan kawasan serupa di Asia Pasifik.

Beberapa tahun belakangan ini telah digulirkan penerapan Free Trade Zone Batam (FTZ Batam), Bintan, dan Karimun yang mengacu pada UU No 36 tentang Kawasan Perdagangan Bebas dan Pelabuhan Bebas dan kemudian dirubah beberapa kali melalui PERPU, sehingga di undangkan menjadi UU no 44 tahun 2007. Ada juga Undang-Undang 36 tahun 2000 Tentang “ 
Penetapan Peraturan Pemerintah Pengganti UU No 1 Tahun 2000 Tentang Kawasan Perdagangan Bebas dan Pelabuhan Bebas Menjadi Undang Undang serta masih banyak Undang-Undang lainnya yang berkaitan dengan FTZ Batam. Kemudian di saat masa akhir jabatan anggota DPR Pusat tahun 2009, bersama dengan pemerintah pusat saat ini sedang membahas mengenai UU Kawasan Ekonomi Khusus (KEK) yang akan memayungi pembentukan Kawasan Ekonomi Khusus di daerah Batam dan daerah lainnya di Indonesia ${ }^{1}$.

Untuk meningkatkan pariwisata Kota Batam, salah satu bentuk program yang dilakukan Dinas Pariwisata Kota Batam adalah Visit Batam 2010. Kegiatan Visit Batam 2010 ini bertujuan menarik wisatawan khususnya wisatawan manca negara. Agar program tersebut dapat berjalan sesuai dengan rencana haruslah memiliki pemikiran yang strategis.

Menurut Cutlip, Center dan Broom dalam bukunya Effective Public Relations (2006:352) mengartikan pemikiran strategis sebagai berikut

Pemikiran strategis adalah memprediksi atau menentukan tujuan masa depan yang di harap kan, menentukan kekuatan apa yang akan membantu atau menghalangi upaya mengejar tujuan, dan merumuskan rencana untuk mencapai keadaan yang diharapkan tersebut.

Visit Batam 2010 ini memiliki 4 pilar dalam rencana program dan kegiatan Visit

1 http://www.bpbatam.go.id/ini/batamGuide/ batam_history.jsp, 31 Mei 2011
Batam 2010, yaitu penataan infrastruktur, penataan objek wisata, event pariwisata dan promosi dan untuk itu, diperlukan suatu strategi komunikasi agar ke 4 pilar dalam visit batam 2010 dapat terlaksana dengan baik.

Seperti yang dikatakan Smith (2005:3) bahwa Strategi komunikasi adalah kegiatan atau kampanye komunikasi yang sifatnya informasial maupun persuasive untuk membangun pemahaman dan dukungan terhadap suatu ide, gagasan atau kasus, produk maupun jasa yang terencanam, yang dilakukan oleh suatu organisasi baik yang berorientasi laba maupun nirlaba, memiliki tujuan, rencana dan berbagai alaternative berdasarkan riset dan memiliki evaluasi.

Visit Batam 2010 dibentuk dari berbagai pihak baik linier maupun non linier. Pihak linear itu terdiri dari Dinas Perhubungan, Dinas Pekerjaan Umum, Dinas Tata Kota, Dinas PMK dan UKM, Badan Pengawasan Batam, Instansi Bandara, Instansi Pelabuhan, Instansi Imigrasi. Sedangkan pihak non linearnya antara lain Persatuan Hotel dan Restoran Indonesia (PHRI) Kota Batam, Asosiasi Agen Travel dan Tour Indonesia (ASITA) Kota Batam, Himpunan Pramuwisata Indonesia (HPI) Kota Batam, dan Perhimpunan Golf Indonesia Kota Batam.

Jika ditinjau dari fungsinya, tim Visit Batam 2010 selain berkewajiban memberikan kenyamanan terhadap para wisatawan, juga dituntut untuk mencapai tingkat keuntungan yang optimal dan sebagai penyumbang pendapatan asli daerah 
(PAD). Kenyamanan wisatawan akan tercapai apabila adanya komunikasi yang efektif diantara tim tersebut. Komunikasi yang efektif dapat terjadi apabila suatu pesan yang diberitahukan komunikator dapat diterima dengan baik atau sama oleh komunikan sehingga tidak terjadi salah persepsi.

Dengan memperhatikan keadaan dan perubahan pembangunan pariwisata dewasa ini beserta tantangan yang ada, sangat perlu dipersiapkan strategi komunikasi yang efektif dalam menunjang pembangunan. Strategi pada hakekatnya adalah suatu perencanaan dan manajemen untuk mencapai tujuan tertentu.

Lionberg dan Gwin (1982:256) menyatakan bahwa strategi komunikasi umumnya dirumuskan dengan memperhatikan tiga hal yaitu khalayak sasaran, pesan yang disampaikan, dan saluran yang digunakan untuk mencapai tujuan tertentu.

Didalam strategi yang baik haruslah memiliki koordinasi tim kerja, memiliki tema, mengidentifikasi faktor pendukung sesuai dengan prinsip-prinsip pelaksanaan gagasan secara rasional, efesien dalam pendanaan dan memiliki taktik untuk mencapai tujuan secara efektif ${ }^{2}$.

Sehingga fokus dari penelitian ini adalah penulis ingin mengetahui bagaimana penataan objek pariwisata sebagai strategi komunikasi Dinas Pariwisata dan Kebudayaan Kota Batam dalam kegiatan 2 http://id.wikipedia.org/wiki/ Strategi, 27 Maret 2011
Visit Batam 2010.

Strategi komunikasi menurut Ucjana (2004:29) merupakan paduan dari perencanaan komunikasi (communication planning) dan manajemen komunikasi (communication management) untuk mencapai suatu tujuan (goal). Untuk mencapai tujuan tersebut strategi komunikasi harus dapat menunjukan bagaimana operasionalnya secara taktik harus dilakukan dalam arti kata bahwa pendekatan bisa berubah-ubah sewaktuwaktu, tergantung pada situasi dan kondisi.

Definisi pariwisata dari dimensi spasial ini di Indonesia didefinisikan sebagai kegiatan wisata, seperti yang tercantum dalam Undang-Undang Kepariwisataan No. 10 tahun 2009 pasal 1, yaitu kegiatan perjalanan yang dilakukan oleh seseorang atau sekelompok orang dengan mengunjungi tempat tertentu untuk tujuan rekreasi, pengembangan pribadi, atau mempelajari keunikan daya tarik wisata yang dikunjungi dalam jangka waktu sementara.

a) Kategori Industri (Bisnis)

Definisi pariwisata yang dipandang dari dimensi industri/bisnis memfokuskan pada keterkaitan antara barang dan jasa untuk memfasilitasi perjalanan wisata.

b) Kategori Akademis

Pariwisata dari dimensi ini didefinisikan sebagai studi yang mempelajari perjalanan manusia keluar dari lingkungannya, juga termasuk industri yang merespon kebutuhan manusia yang melakukan perjalanan, lebih jauh lagi 
dampak yang ditimbulkan oleh pelaku perjalanan maupun industri terhadap lingkungan sosial budaya, ekonomi, maupun lingkungan fisik setempat. Definisi tersebut dikemukakan oleh Jafar Jafari, 1977 (Gartner, 1996: 7).

"Tourism is a study of man away from his usual habitat, of the industry which responds to his needs and of the impacts that both he and the industry have on the host sosiocultural, economic and physical environment".

b. Kategori Sosial dan Budaya

Definisi pariwisata dari dimensi sosial budaya menitik beratkan perhatian pada:

1) upaya memenuhi kebutuhan wisatawan dengan berbagai karakteristiknya, seperti definisi yang dikemukakan oleh Mathieson and Wall, 1982 (Gunn, 2002: 9) berikut ini:

"Tourism is the temporary movement of people to destinations outside their normal places of work and residence, the activities undertaken during their stay in those destinations, and the facilities created to cater to their needs".

2) interaksi antara elemen lingkungan fisik, ekonomi, dan sosial budaya, seperti yang dikemukakan oleh Leiper, 1981 (Gartner, 1996: 6) yang mendefinisikan pariwisata sebagai

"an open system of five elements interacting with broader environments; the human element; tourists; three geographical elements: generating region, transit route, and destination region; and an economic element, the tourist industry. The five are arranged in functional and spatial connection, interacting with physical, technological, social, cultural, economic, and political factors. The dynamic element comprises persons undertaking travel which is to some extent, leisure-based and which involves a temporary stay away from home of at least one night".

3) kerangka sejarah dan budaya, seperti yang dikemukakan oleh MacCannell, 1992 (Herbert, 1995: 1) berikut ini

"Tourism is not just an aggregate of merely commercial activities; it is also an ideological framing of history, nature and tradition; a framing that has the power to reshape culture and nature to its own needs".

Dalam penelitian ini, penulis menggunakan metode penelitian kualitatif. Metode penelitian kualitatif yang dimaksud adalah metode yang menghasilkan penemuan-penemuan yang tidak dicapai dengan menggunakan prosedur statistik atau cara kuantifikasi lainnya.

Pendekatan yang digunakan dalam 
penelitian ini dengan pendekatan studi kasus yang bersifat eksplanatori, yang bertujuan untuk memberikan penjelasan detail biasanya dengan menggunakan "Bagaimana" dan "Mengapa" karena pada dasarnya lebih mengarah kepada penggunaan strategi-strategi studi kasus, historis dan eksperimen mengenai permasalahan yang ada atau dikatakan sebagai penelitian eksplanatori (Yin: 2008: 9). Sumber data yang digunakan yaitu (1) Sumber data primer yaitu data primer yang dimaksud berupa kata-kata, tindakan, data tertulis, dan gambar, yang dapat diperoleh melalui observasi, dan wawancara, (2) Sumber data sekunder yaitu data yang diperoleh dari sumber lain secara tidak langsung, yang dapat diperoleh melalui dokumen-dokumen resmi yang berkaitan dengan obyek penelitian baik secara nasional, catatan-catatan penunjang, dan literatur, buku-buku perpustakaan, dokumentasi, arsip-arsip dan keteranganketerangan lain yang berhubungan dengan masalah penelitian yang digunakan sebagai pelengkap dan pendukung dari data primer.

Dalam menentukan sumber data, penulis menggunakan purposive sampling, atau sampel bertujuan, yang dipilih berdasarkan kepentingan penelitian atau sudah terencana sebelumnya. Daymon dan Halloway dalam bukunya Riset Kualitatif dalam Public Relations dan Marketing Communications (2002:243) mengatakan:

Penelitian dalam pendekatan kualitatif memiliki sampel yang bertujuan (purposeful), artinya sampel yang ditarik atau diambil berdasarkan tujuan penyelidikan. Peneliti mengumpulkan bukti dari satu porsi (atau satu "sampel") dari populasi yang peneliti minati. Dalam penelitian ini terdapat 11 sampel yang sebagai nara sumber yaitu: (1) Kabid Promosi Dinas Pariwisata dan Kebudayaan Kota Batam,(2) Kabid Sarana Objek Wisata Dinas Pariwisata dan Kebudayaan Kota Batam,(3) Kasi Perfilman Dinas Pariwisata dan Kebudayaan Kota Batam, (4) Kasi Seni dan Budaya Dinas Pariwisata dan Kebudayaan Kota Batam, (5) Asosiasi Jasa dan Travel Agent Kota Batam (ASITA), (6) Asosiasi Jasa Hiburan Barelang kota Batam (AJAHIB), (7) Himpunan Pramuwisata Indonesia kota Batam (HAPI), (7) Wartawan Batam Pos (Koran terbesar di Batam), (8) Wartawan Batam TV (TV lokal pertama di Batam)(9) Polisi Pariwisata Kota Batam, (10) Pengamat Pariwisata Kota Batam.

Pengumpulan data dalam penelitian ini adalah (1) Studi Dokumentasi, Data tersebut tidak hanya berasal dari Dinas Pariwisata dan Kebudayaan tempat peneliti mengadakan penelitian tetapi bisa juga berasal dari lembaga lain yang terkait seperti perpustakaan, serta internet, (2) Wawancara Mendalam, Wawancara yang peneliti lakukan terhadap informan dilakukan secara mendalam (depth interview). Dalam wawancara mendalam, peneliti berupaya menyelam ke dalam dunia mereka.

Peneliti menggunakan analisis data Miles dan Huberman (1992:1521) yang menjelaskan tentang proses analisis menjadi langkah-langkah sebagai 
berikut: (a) Tahap pertama, kategorisasi dan mereduksi data, yakni melakukan pengumpulan terhadap semua informasi penting yang terkait dengan masalah penelitian, selanjutnya data dikelompokan sesuai dengan topik permasalahan, (b) Tahap kedua, data yang dikelompokan selanjutnya disusun dalam bentuk narasinarasi, sehingga data berbentuk rangkaian informasi yang bermakna sesuai dengan masalah penelitian, (c) Tahap ketiga, melakukan interpretasi pada data, yaitu dengan menginterpretasikan apa yang telah diberikan dan diinterpretasikan informan terhadap masalah yang diteliti, (d) Tahap keempat, pengambilan kesimpulan berdasarkan susunan narasi yang telah disusun pada tahap ketiga, sehingga dapat memberikan jawaban atas masalah penelitian, (e) Tahap kelima, melakukan verifikasi hasilanalisa data dengan informan, yang didasarkan pada simpulan tahap keempat. Tahap ini dimaksudkan untuk menghindari kesalahan interpretasi dari hasil wawancara dengan sejumlah informan penelitian yang dapat mengabarkan makna persoalan sebenarnya dari penelitian ini.

\section{PEMBAHASAN}

Ada 5 program yang difokus pada penataan objek wisata Dinas Pariwisata dan Kebudayaan dalam Kegiatan Visit Batam 2010 yaitu

1) Penataan dan peningkatan objek wisata Pantai Dendang Melayu di Jembatan Raja Ali Haji Fisabillah.
Penataan dan peningkatan objek wisata Pantai Dendang Melayu di Jembatan Fisabillah dilakukan melalui pemasangan lampu hias jembatan, (2) pemeliharaan jembatan Raja Ali Haji Fisabillah, (3) pembangunan tempat Parkir, (4) pembangunan panggung terbuka, (5) pembangunan pendestrian jalan dibawah jembatan, (6) pembangunan sarana permainan anak, (7) penataan pedagang kaki lima.

2) Peningkatan dan penataan objek wisata Pantai Melayu Pulau Rempang Peningkatan dan penataan objek wisata Pantai Melayu dan Rempang melalui (1) peningkatan jalan menuju kawasan Pantai Melayu, (2) pembangunan dan penataan sarana dan objek wisata Pantai Melayu

3) Peningkatan dan penataan objek wisata Pantai Melur Pulau Galang Peningkatan dan penataan objek wisata Pantai Melur di Pulau Galang melalui (1) peningkatan jalan menuju Pantai Melur, (2) pembanguna dan penataan sarana dan objek wisata Pantai Melur

4) Pembangunan dan penataan kios pasar kota Batam

Pembangunan dan penataan kios pasar Kota Batam dilakukan di beberapa tempat seperti batam center dan batu besar. Kios-kios tersebut di kelola oleh masyarakat, agar apa yang dihasilkan masyarakat dapat langsung di rasakan kembaliolehmasyrakat tersebut. Seperti kios kerajinan Bunga Gong-gong yang 
ada di Batu Besar, kios tersebut di kelola oleh ibu-ibu PKK di Batu Besar, mereka membuat kerajinan dari Gonggong. Gonggong adalah sejenis kerang yang di komsumsi di masyarakat Batam, bentuk cangkangnya seperti keong. Nah Gongong yang sudah kosong tersebut dicuci bersih terus di jemur, lalu gongong tersebut di bentuk sesuai keinginan, yang menjadi kekhasan disini adalah Gongong tersebut di rangkai menjadi seperti bunga.

5) Pengembangan wisata bahari Pulau Abang dan sekitarnya

Pengembangan wisata bahari Pulau Abang masih dalam tahap rencana. Pulau Abang ini memiliki pesona wisata bawah laut yang masih asli. Di rencanakan akan ada 3 tempat wisata yaitu Pulau Abang, Pulau Hantu dan Pulau Ranom. Pulau Abang di rencanakan untuk kegiatan wisata Diving dan Snorkling, Pulau Hantu untuk menginap, dan pulau Ranom untuk kegiatan Memamcing.

Penataan objek wisatajuga merupakan salah bentuk strategi komunikasi yang dilakukan oleh Dinas Pariwisata dalam kegiatan Visit Batam 2010. Objek Wisata adalah berbagai macam hal yang dapat dilihat, disaksikan, dilakukan atau dirasakan (Yoeti, 1997). Objek wisata merupakan daya tarik bagi wisatawan untuk berwisata ke daerah tertentu. Oleh karna itu objek wisata haruslah di tata sedemikian rupa agar dapat menarik wisatawan.
Penataan objek wisata yang dilakukan Dinas Pariwisata dan Kebudyaan Kota Batam tidak berkelanjutan, seperti halnya penataan pasar kios yang di lakukan Dinas Pariwisata dan Kebudayaan Kota Batam tidakjalan. Kegiatan tersebut hanya sebentar saja, terlihat dari kondisi kios-kios yang selalu tutup ketika penulis mengunjungi pasar kios tersebut, salah satunya Pasar Kios yang ada di Batu Besar. Pasar kios tersebut dikelola oleh ibu-ibu PKK yang tinggal di Kampung Melayu, Batu Besar.

Menurut Suwantoro (1997:19) Objek wisata dikelompokan menjadi 3 golongan, yaitu (1) Obyek wisata dan daya tarik wisata alam. Obyek wisata yang daya tariknya bersumber pada keindahan dan kekayaan alam yaitu (1) Obyek wisata dan daya tarik budaya, (2) Obyek wisata dan daya tarik pada minat khusus.

Dinas Pariwisata dan Kebudayaan harus mempertimbangkan jenis pariwisata apa yang cocok dengan Kota Batam sehingga dalam penataan objek wisata tidak menjadi sia-sia. Hasil wawancara dengan Ibu Kadek, ketua ASITA Batam mengatakan bahwa Kota Batam minim dengan objek Wisata

"Susah-susah gampang ya. Masalahnya Kota Batam ini minim objek wisata. Sehingga kami terpaksa combined dengan spa. Di Batam ini menjamur sekali tempat spa dan refleksi".

Menurut penulis, saat ini pariwisata yang sesuai untuk dikembangkan di Kota Batam adalah Pariwisata Perkotaan. 
Klingner (2006: 1) mendefinisikan pariwisata perkotaan secara sederhana sebagai

"Sekumpulan sumber daya atau kegiatan wisata yang berlokasi di kota dan menawarkannya kepada pengunjung dari tempat lain”.

Ada beberapa tipologi dari pariwisata perkotaan yang di kemukakan oleh Law (1996: 2-3) , antara lain (a) Ibu kota: memiliki peran administratif dan bisnis yang dapat menarik wisatawan. Biasanya memiliki museum nasional, bangunan, dan monumen memiliki nilai sejarah nasional, (b) Kota-kota industri: karakter dan citra industrial menjadi daya tarik bagi wisatawan, (c) Kota dengan high-amenities: memiliki beragam fasilitas dari mulai pemandangan alam, hiburan, sampai bisnis yang dapat menarik wisatawan, (d) Kotakota daya tarik utama: kota yang fokus pada wisatawan dari luar daerahnegara, biasanya kota dengan multifungsi.

Dari tipologi pariwisata perkotaan diatas, kota Batam sesuai sebagai kota dengan high-amenities. Pulau Batam merupakan pulau transit bagi para wisatawan baik wisatawan domestik maupun manca Negara, oleh karna itu kota Batam memiliki beragam fasilitas mulai dari pemandangan alam berupa laut, hiburan seperti banyaknya mall-mall, diskotik, tempat kara oke, spa, reso, city hotel,dan tempat Bisnis seperti ruko yang hampir di bangun merata di seluruh kota Batam.

Objek wisata yang cocok dengan Kota Batam adalah objek wisata dengan minat khusus, seperti olah raga. Dinas Pariwisata dan Kebudayaan harus memfokuskan kepada fasilitas yang mengarah olah raga, seperti pengadaan fasilitas olah raga, seperti Gelanggang Olah Raga, Area Bermain, Lapangan Olah Raga umum, Area Mancing yang menyebar rata di kota Batam. Selanjutnya Dinas Pariwisata menawarkan paket wisata yang di buat khusus oleh Dinas Pariwisata dan Kebudayaan kota Batam dan di tawarkan kepada pelaku bisnis pariwisata kota Batam, agar mereka bisa membuat internary paket wisata tersebut. Setiap event olah raga yang akan diadakan di kota Batam, haruslah melibatkan para pelaku pariwisata khusunya agen travel. Sehingga wisata minat khusus itu bisa dijadikan komoditi bagi pemerintah Kota Batam.

Penataan Kios akan maju, jika Dinas Pariwisata dan Kebudayaan melakukan pemberdayaan bagi wilayah atau kecamatan yang ada di Kota Batam. Dimana wilayah tersebut nantinya bisa menghasilkan 1 jenis produk unggulan dengan istilah 1 kampong 1 produk (SKSP). Contohnya di wilayah kecamatan Nongsa, kampong melayu, Batu Besar, sudah ada Kios Kerajinan Bunga Gong-gong yang di kelola oleh Ibuibu PKK setempat. Dinas Pariwisata dan Kebudayaan Kota Batam harus bekerja sama dengan Dinas UMKM melakukan beberapa hal seperti (1) Memberikan pelatihan kepada ibu-ibu PKK dalam hal merangkai dan mengemas yang baik hasilnya layak untuk dijual, (2) Ibu-ibu pkk tersebut diwajibkan untuk membina satu kelompok yang terdiri dari 5 orang, 
untuk memberikan pelatihan dari apa yang mereka dapat, (3) Dinas Pariwisata dan Kebudayaan memberikan modal awal untuk memulai pasr kios tersebut, (4) Dinas UMKM memberikan pinjaman lunak, (5) Dinas Pariwisata dan Kebudayaan memfasilitasi untuk mempromosikan hasil produk tersebut kepada masyarakat di tiap event-event promosi.

Produk yang di hasilkan pada tiap kecamatan pasti berbeda, tergantung pada keahlian dan tradisi masyarakat setempat. Program ini harus direncanakan dalam jangka waktu yang panjang, tiap progresitasnya harus di catat dengan baik, dan secara tidak langsung, kampong yang di berdayakan tersebut akan menjadi objek wisata.

\section{PENUTUP}

Peningkatan Objek Wisata sebagai strategi komunikasi dalam kegiatan Visit Batam 2010 ini dilakukan dengan berbagai cara antara lain (1) Penataan dan peningkatan objek wisata Pantai Dendang Melayu di Jembatan Raja Ali Haji Fisabillah, (2) Peningkatan dan penataan objek wisata Pantai Melayu Pulau Rempang, (3) Peningkatan dan Penataan Objek wisata Pantai Melur Pulau Galang, (4)Pembangunan dan penataan Kios Pasar seni Kota Batam, (5) Pengembangan objek wisata Pulau Abang dan Sekitarnya. Penataan objek wisata yang dilakukan Dinas Pariwisata dan Kebudyaan Kota Batam tidak berkelanjutan, seperti halnya penataan pasar kios yang di lakukan Dinas Pariwisata dan Kebudayaan Kota Batam tidak jalan. Kegiatan tersebut hanya sebentar saja, terlihat dari kondisi kios-kios yang selalu tutup ketika penulis mengunjungi pasar kios tersebut, salah satunya Pasar Kios yang ada di Batu Besar. Pasar kios tersebut dikelola oleh ibu-ibu PKK yang tinggal di Kampung Melayu, Batu Besar. Dinas Pariwisata dan Kebudayaan harus mempertimbangkan jenis pariwisata apa yang cocok dengan Kota Batam sehingga dalam penataan objek wisata tidak menjadi sia-sia. Pariwisata yang sesuai untuk dikembangkan di Kota Batam adalah Pariwisata Perkotaan. Penataan Kios akan maju, jika Dinas Pariwisata dan Kebudayaan melakukan pemberdayaan bagi wilayah atau kecamatan yang ada di Kota Batam. Dimana wilayah tersebut nantinya bisa menghasilkan 1 jenis produk unggulan dengan istilah 1 kampong 1 produk (SKSP). Contohnya di wilayah kecamatan Nongsa, kampong melayu, Batu Besar, sudah ada Kios Kerajinan Bunga Gong-gong yang di kelola oleh Ibu-ibu PKK setempat 


\section{DAFTAR PUSTAKA}

Ashworth G.J. dan Tunbridge, J.E. 1990. The Tourist-Historic City. John Wiley\&Sons, England.

Biederman, Paul S., ect. 2007. Travel and Tourism: An Industry Primer. Pearson Education, Inc. Upper Saddle River, NJ.

Bungin, Burhan. 2003. Analisis Data Penelitian Kualitatif. Jakarta. Raja Grafindo Persada.

Cutlip, Scott M, Center, Alen H, \& Broom, Glen M. 2006. Effektive Public Relations. Terjemahan Tri Wibowo, B.S. Jakarta. Kencana.

Edgell Sr, David L., Allen, Maria D., Smith, G., Jason, R. Swanson. 2008. Tourism Policy and Planning: Yesterday, Today, and Tomorrow. Elsevier, Burlington.

Fandeli, Chafid, 1997. Dasar-dasar Manajemen Kepariwisataan Alam. Liberty. Yogyakarta.

Goeldner, CharlesA. andJ.R.BrentRitchie.2006.Tourism:Principles, Practices, Philosophies. 10th ed. Wiley, Hoboken, NJ.

Gozali, Dodi M. 2005. Communication Measurment, Konsep dan Aplikasi Pengkuran Kinerja Public Relations. Bandung. Simbiosa Rekatama Media.

Gulo, W. 2003. Metodologi Penelitian. Jakarta. Grasindo.

Inskeep, Edward. 1991. Tourism Planning- An Integrated Sustainable Approach. Van Nostrand Reinhold. New York.

Kodhyat H, 1996. Sejarah Pariwisata dan Perkembangannya di Indonesia. Grasindo. Jakarta.

Komari SS, Ta’In. 2008. Batam Tergadai 70 Tahun. Batam. Kelompok Diskusi Anti 86.

Miles, Matthew B dan Huberman, A. Michael, 1992. Analisis Data Kualitatif. UI Press. Jakarta.

Moleong, Lexy J, 2002. Metode Penelitian Kualitatif. PT. Remaja Rosdakarya. Bandung.

Mulyana, M.A, Ph.D, Prof. Deddy. 2008.Komunikasi Massa. Bandung. Widya Padjajaran.

Nazir Ph.D,Moh. 2003. Metode Penelitian. Jakarta. Ghalia Indonesia.

Page, Stephen J. dan Hall, Michael C. 2003. Managing Urban Tourism. Pearson Education Limited. Harlow.

Page, Stephen. 1995. Urban Touris. Routledge. London. 
Patilima, Hamid. 2007. Metode Penelitian Kualitatif. Bandung. Alfabeta.

Prijana M.si \& Semendison S.U,Drs.Ins. 2005. Metode Sampling Untuk Penelitian Sosial. Bandung. Humaniora.

Richard, Greg dan Wilson, Julie. 2007. Tourism, Creativity, and Development. Routledge. Oxon.

Soekadijo, R. G, 1997. Anatomi Pariwisata : Memahami Pariwisata Sebagai Sistem Linkage. Gramedia Pustaka Utama. Jakarta.

Strauss,Aselm \& Corbin,Juliet. 2003. Dasar-dasar Penelitian Kualitatif. Terjemahan Muhammad Shodiq \& Imam Muttaqien. Yogyakarta. Pustaka Pelajar Offset.

Subyantoro,Arief \& Suwarto,FX. 2007. Metode dan Teknik Penelitian Sosial. Yogyakarta. Andi.

Suprapto MS, Drs Tommy. 2006. Pengantar Teori Komunikasi. Yogyakarta. Media Pressindo.

Tarigan, DRS.Josep R \& Suparmoko,MA,Ph.D,Drs.M. 2000. Metode Pengumpulan Data, Untuk Ilmu-ilmu Sosial dan Ekonomi. Yogyakarta. BPFE-Yogyakarta.

Uchjana,Prof.Onong. 2003. Ilmu, Teori dan Filsafat Komunikasi. Bandung. Citra Aditya Bakti.

Yin, Prof.Dr.Robert K. 1996. Studi Kasus, Desain dan Metode. Raja Grafindo Persada. Jakarta.

Yoeti, Oka A, 1990. Pengantar Ilmu Pariwisata. Angkasa. Bandung.

Yoeti, Oka A, 1997. Perencanaan dan Pengembangan Pariwisata. PT. Pradnya. Paramita. Jakarta. 